\title{
High pressure differential scanning calorimetry of the hydrothermal salt solutions $\mathrm{K}_{2} \mathrm{SO}_{4}-\mathrm{Na}_{2} \mathrm{SO}_{4}-\mathrm{H}_{2} \mathrm{O}$ and $\mathrm{K}_{2} \mathrm{HPO}_{4}-\mathrm{H}_{2} \mathrm{O}$
}

\author{
Joachim Reimer ${ }^{a}$ and Frédéric Vogel ${ }^{* a b}$ \\ Aqueous salt solutions under hydrothermal conditions play an important role in geochemistry as well as in \\ processes using hot compressed water as the process medium such as supercritical water oxidation (SCWO) \\ and supercritical water gasification (SCWG). Isochoric high pressure differential scanning calorimetry (HP- \\ DSC) was used as an accurate technique to investigate the phase behavior of such solutions under \\ hydrothermal conditions. New data in the low concentration range (0.14-15.0 mass\%) has been \\ collected for the binary systems $\mathrm{K}_{2} \mathrm{SO}_{4}-\mathrm{H}_{2} \mathrm{O}, \mathrm{Na}_{2} \mathrm{SO}_{4}-\mathrm{H}_{2} \mathrm{O}$ and $\mathrm{K}_{2} \mathrm{HPO}_{4}-\mathrm{H}_{2} \mathrm{O}$. Furthermore we have \\ discovered a liquid-liquid immiscibility in the ternary system $\mathrm{K}_{2} \mathrm{SO}_{4}-\mathrm{Na}_{2} \mathrm{SO}_{4}-\mathrm{H}_{2} \mathrm{O}$, which has not been \\ reported before.
}

Received 18th July 2013

Accepted 2nd October 2013

DOI: $10.1039 / c 3 r a 43725 f$

www.rsc.org/advances

\section{Introduction}

Aqueous salt solutions under hydrothermal conditions play an important role in geochemistry as well as in processes using hot compressed water as the process medium such as supercritical water oxidation (SCWO) and supercritical water gasification (SCWG). Salt solubility and phase behavior of the solutions are crucial e.g. for understanding ore formation ${ }^{1}$ and for the salt management in technical SCW processes..$^{2-4}$

At the Paul Scherrer Institute a hydrothermal gasification process was developed to produce methane from wet biomass. ${ }^{5}$ Inorganic compounds in the biomass feedstock can cause problems in the process by poisoning the methanation catalyst or lead to a blocking due to precipitation of solid salt at supercritical conditions. Therefore the inorganic salts have to be removed from the feed stream. Furthermore the separation of inorganic salts from the feed stream opens the possibility to recover nutrients such as phosphorus, potassium and ammonia, which could again be used as fertilizer in biomass production.

To optimize this salt separation process a detailed knowledge of the phase behavior of salt solutions is needed.

Historically, binary phase diagrams of aqueous salt solutions were divided into two major groups. The first group (type 1) has a continuous solubility line from the triple point of pure water to the triple point of the pure salt. Salts with type 1 behavior include e.g. halides and nitrates. The second group (type 2) is characterized by a solubility line that intersects the critical line

${ }^{a}$ Paul Scherrer Institute, Laboratory for Bioenergy and Catalysis, OVGA/104, CH-5232 Villigen PSI, Switzerland. E-mail: Frederic.vogel@psi.ch; Fax: +41 56 3102199; Tel: +41563102135

${ }^{b}$ Fachhochschule Nordwestschweiz, 5210 Windisch, Switzerland in a lower critical endpoint $\mathrm{p}$ and a higher critical endpoint $\mathrm{q}$. Between those invariant points the fluid is in equilibrium with the solid salt phase. Typical type 2 salts are sulfates, carbonates, silicates and oxides. Often phase diagrams of both types are complicated by liquid-liquid immiscibilities. Valyashko derived a set of phase diagrams for all possible cases. ${ }^{6}$

Aqueous $\mathrm{Na}_{2} \mathrm{SO}_{4}$ and $\mathrm{K}_{2} \mathrm{SO}_{4}$ solutions are known to have a phase diagram of type $2 \mathrm{~d}^{\prime}$ (ref. 7) which possesses a metastable liquid-liquid immiscibility. $\mathrm{K}_{2} \mathrm{HPO}_{4}-\mathrm{H}_{2} \mathrm{O}$ is known for its type $1 \mathrm{~d}$ behavior exhibiting a stable liquid-liquid immiscibility below the liquid 1-gas critical endpoint R.7 The schematic $T-x$ projections of the two phase diagrams of interest (type 1d, $2 \mathrm{~d}^{\prime}$ ) are shown in Fig. 1.

As in naturally occurring salt solutions typically more than one salt is dissolved, higher order mixtures are also of interest. In the phase diagrams of such solutions the properties of one binary mixture transform into the properties of the second binary mixture, and this leads to either continuous critical lines or invariant critical endpoints. ${ }^{6}$ Valyashko also developed a system to classify these phase diagrams. ${ }^{6}$ The ternary system $\mathrm{K}_{2} \mathrm{SO}_{4}-\mathrm{Na}_{2} \mathrm{SO}_{4}-\mathrm{H}_{2} \mathrm{O}$ was studied up to $200{ }^{\circ} \mathrm{C}$ by Freyer and Voigt $^{8}$ who reported the formation of the double salt Glaserite of the formula $\mathrm{NaK}_{3}\left(\mathrm{SO}_{4}\right)_{2}$ in certain concentration ranges, also with varying $\mathrm{Na}: \mathrm{K}$ ratios.

In earlier investigations from our group ${ }^{9-11}$ the continuous salt separation from hydrothermal salt solutions was investigated. Binary type 1 salt solutions showed high separation efficiencies, whereas type 2 solutions showed low separation efficiencies and caused deposition of solid salt in the apparatus. Interestingly, a ternary solution of the two type 2 salts $\mathrm{Na}_{2} \mathrm{SO}_{4}$ and $\mathrm{K}_{2} \mathrm{SO}_{4}$ could also be recovered efficiently. The salt deposition in the salt separation unit was studied with neutron 
Type 1d

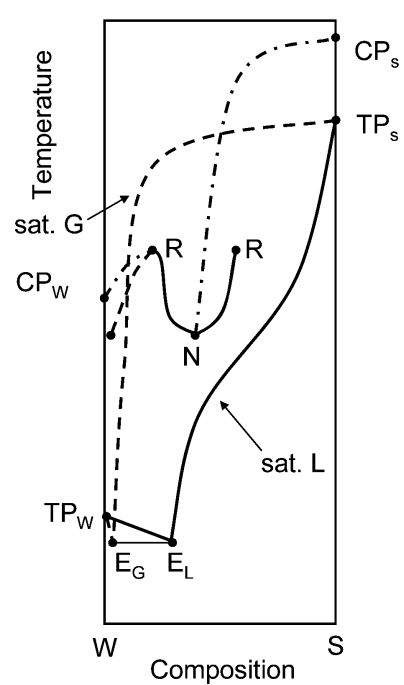

Type $2 d^{c}$

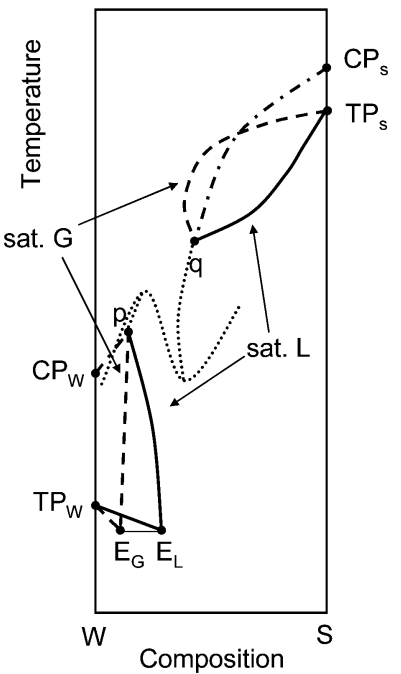

Fig. $1 T-x$ projections of type $1 d$ and $2 d^{\prime}$ schematic phase diagrams. Bold lines liquid composition at the three phase equilibrium ( $\mathrm{G}-\mathrm{L}-\mathrm{S}$ and $\mathrm{G}-\mathrm{L} 1-\mathrm{L} 2$ ); dashed lines - gas phase composition at the three phase equilibrium (G-L-S and G-L1L2); dash-dotted lines - critical curves; dotted lines - metastable liquid-liquid immiscibility. $E_{\mathrm{G}}$ - composition of gas phase at eutectic equilibrium ( $\mathrm{G}-\mathrm{L}-\mathrm{S}_{\mathrm{W}}-\mathrm{S}_{\mathrm{S}}$ ); $E_{\mathrm{L}}$ - composition of liquid phase at eutectic equilibrium $\left(\mathrm{G}-\mathrm{L}-\mathrm{S}_{\mathrm{W}}-\mathrm{S}_{\mathrm{S}}\right) ; \mathrm{TP}_{\mathrm{W}_{1}} \mathrm{TP}_{\mathrm{S}}-$ triple point of pure water and pure salt, respectively; $C P_{W}, C P_{S}-$ critical points of pure water and pure salt, respectively; $\mathrm{N}$ - lower critical end-point ( $L 1=\mathrm{L} 2-\mathrm{G}) ; \mathrm{R}-$ upper critical end-point $(\mathrm{L} 1=\mathrm{G}-\mathrm{L} 2) ; \mathrm{p}, \mathrm{q}$-critical end-points $\left(\mathrm{G}=\mathrm{L}-\mathrm{S}_{\mathrm{S}}\right)$. Adapted from Valyashko. ${ }^{6}$

radiography on the macro-scale..$^{\mathbf{1 2 - 1 4}}$ The salt precipitation and separation in connection with SCWG and SCWO processes was also studied in other groups using different approaches e.g. precipitation on a hot finger, special reactor designs (e.g. MODAR reactor, transpiring wall reactor)., ${ }^{2,3,15-21}$ The results of these studies are often affected by the design of the used setup and restricted to the range of the parameters $(p, T, x)$ varied.

For a better understanding of the phase behavior of salt solutions we used differential scanning calorimetry as a thermal analysis tool to investigate the phase transitions in such solutions. Thermal analysis is a sensitive and accurate tool to investigate phase transitions and phase behavior. ${ }^{22,23}$ Differential Scanning Calorimetry (DSC) is very sensitive towards phase transitions accompanied by changes in the heat capacity of the sample. The DSC measures the heat flow into or out of the sample versus a reference. Changes in the heat capacity of the sample due to phase transitions lead to step or peak shaped signals in the heat flow curves. The measured heat flow is proportional to the sample mass, the heating/cooling rate and the specific heat capacity $\left(c_{\mathrm{V}}\right)$ of the sample (eqn (1)) and in addition to that affected by an instrumental baseline.

$$
\Phi_{\text {measured }}=\Phi_{\text {sample }}+\Phi_{\text {baseline }}=c_{\mathrm{v}} m \beta+\Phi_{\text {baseline }}
$$

As a result of this relation the signal intensity increases with high scanning rates, but often smaller thermal effects vanish at such high rates due to intense broad signals of stronger effects. This led to problems in the interpretation of the heat flow curves in earlier investigations in our group ${ }^{24}$ where a very high scanning rate of $10 \mathrm{~K} \mathrm{~min}^{-1}$ had been chosen.

To test the method for accuracy we first measured salt solutions of $\mathrm{Na}_{2} \mathrm{SO}_{4}$, which have been studied extensively before. ${ }^{25-35}$ For $\mathrm{K}_{2} \mathrm{SO}_{4}$ and $\mathrm{K}_{2} \mathrm{HPO}_{4}$ much less data is available in the literature. Subsequently, measurements above $200{ }^{\circ} \mathrm{C}$ on the ternary system $\mathrm{Na}_{2} \mathrm{SO}_{4}-\mathrm{K}_{2} \mathrm{SO}_{4}-\mathrm{H}_{2} \mathrm{O}$ were performed.

\section{Experimental section}

All experiments were conducted on a Sensys DSC manufactured by SETARAM, France. The calorimeter is equipped with a Calvetstyle sensor, which allows high precision measurements, since the sensor covers almost the whole sample leading to a higher amount of the heat flow being detected, compared to plate type DSC where the sensors only capture the heat flow through the bottom plate of the sample container. The temperature and energy calibration of the instrument were verified with samples of indium, tin, lead and zinc, to cover the whole temperature range of the investigations. All metals had a purity of $>99.999 \%$, except indium which had a purity of $>99.995 \%$, and were supplied by the manufacturer of the instrument.

The salt solutions were prepared gravimetrically with an accuracy of $\pm 0.1 \mathrm{mg}$ and then weighed into the Incoloy crucibles with the same accuracy. Deionized water and salts with a purity $>99.5 \%$ were used for the sample preparation. The crucibles are rated up to $50 \mathrm{MPa}$ at $600{ }^{\circ} \mathrm{C}$. The inner volume of the crucibles was determined to be $128.63 \pm 0.54 \mu \mathrm{L}$ (95\% confidence interval) by fully filling them with water at $25{ }^{\circ} \mathrm{C}$ and weighing.

The crucibles were filled with $38.6 \pm 0.1 \mathrm{mg}$ of the liquid sample, and therefore the average density was $300 \pm 1 \mathrm{~kg} \mathrm{~m}^{-3}$. An empty crucible was used as reference.

During the measurement the sensor was flushed with $20 \mathrm{~mL}$ $\mathrm{min}^{-1}$ of argon. The heating rate was $10 \mathrm{~K} \mathrm{~min}^{-1}$ for the heat-up phase. After an isothermal step of $1 \mathrm{~h}$ the measurement started with a heating/cooling rate of $0.1 \mathrm{~K} \mathrm{~min}^{-1}$.

The experimental data was treated with the Calisto Software (AKTS, Switzerland). Typically a smoothing of 25-50 points was necessary. Multiple measurements were performed to determine the uncertainty of the measurement.

The differences in the isochoric heat capacity $\left(\Delta c_{\mathrm{V}}\right)$ of the samples before and after a phase transition were determined using the glass transition tool of the Calisto software. This tool constructs tangents to the heat flow curves before and after a step-shaped transition and then calculates the $\Delta c_{\mathrm{V}}$ from the intersection points of those tangents with a tangent on the inflection point of the curve using the following relation (eqn (2)):

$$
\Delta c_{\mathrm{v}}=\frac{\left(\Phi_{\text {final }}-\Phi_{\text {initial }}\right)}{m \beta}
$$

\section{Results and discussion}

\section{$\mathrm{Na}_{2} \mathrm{SO}_{4}-\mathrm{H}_{2} \mathrm{O}$}

All the heat flow curves of the system $\mathrm{Na}_{2} \mathrm{SO}_{4}-\mathrm{H}_{2} \mathrm{O}$ show two signals. Upon heating the first signal is an endothermic peak. 
This signal is attributed to the appearance of a solid phase (G-L $\rightarrow$ G-L-S). Comparison of the heat flow curves with those obtained from experiments in the cooling mode showed that the precipitation of the solid salt is kinetically hindered when the measurement is performed in the heating mode and that substantial superheating occurs. Hence, the samples were remeasured in the cooling mode, showing much lower transition temperatures and step-like signals (Fig. 2). The second signal is an exothermic step and it is believed to be the disappearance of the gas phase or the liquid phase, leading to a one phase fluid (F) in equilibrium with a solid salt (G-L-S $\rightarrow$ F-S). The negative value of the difference in the isochoric heat capacity $\left(\Delta c_{\mathrm{V}}\right)$ underlines this assumption. The temperature for this transition at an average density of $300 \mathrm{~kg} \mathrm{~m}^{-3}$ and an initial salt concentration of 1.39 mass $\%$ was $375.2 \pm 0.1{ }^{\circ} \mathrm{C}$ which is in accordance with the data of Valyashko et al. ${ }^{35}$ who obtained in a similar experiment a transition temperature of $374.97 \pm 0.17^{\circ} \mathrm{C}$ for a 1 mass\% solution at an average density of $309.9 \mathrm{~kg} \mathrm{~m}^{-3}$. The expected $\lambda$-shape of the second signal is less pronounced in the heating mode. In the cooling mode it is more pronounced.

From the transition temperatures a part of the phase diagram can be constructed by correcting the concentration of the liquid phase with the method proposed by Valyashko et al. ${ }^{35}$ using the density data from Khaibullin and Novikov. ${ }^{29}$ This correction is needed because water evaporates from the starting solution during heating and therefore the salt concentration in the liquid phase increases. Concentrations of the salt in the vapor phase are normally very small compared to the concentration in the liquid phase and were thus neglected here.

The thermal expansion of the crucible was calculated from the material constants. The expansion of the crucibles due to pressure changes were taken into account. Furthermore we relied on the vapor density data available in the literature and did not use any data on the vapor density from databases or calculations. The uncertainties for the liquid concentration were estimated by calculation of the liquid concentration for extreme values of the liquid and vapor density, as proposed by Valyashko et al. $^{35}$

Our corrected measurements are presented in Table 1. A comparison with literature data is shown in Fig. 3. The data

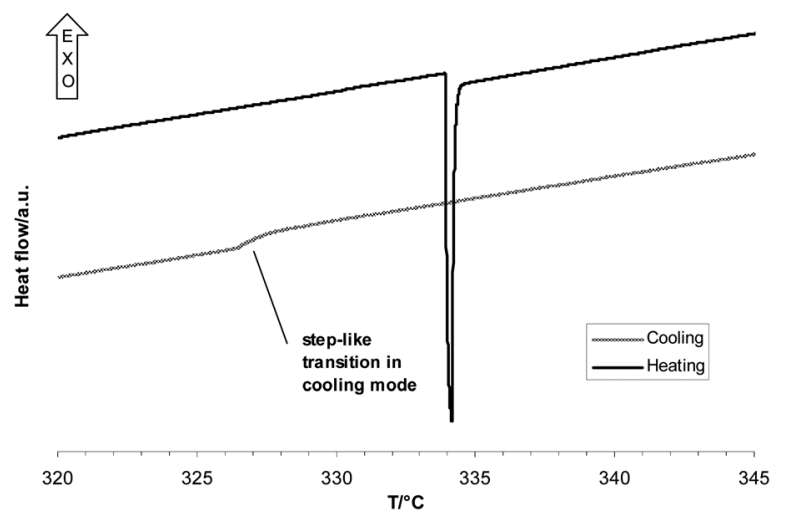

Fig. 2 Comparison of the heat flow signals in heating and cooling mode at $0.1 \mathrm{~K}$ $\min ^{-1}, 6.69$ mass $\% \mathrm{Na}_{2} \mathrm{SO}_{4}$, average density $300 \mathrm{~kg} \mathrm{~m}^{-3}$.
Table 1 Results for $\mathrm{Na}_{2} \mathrm{SO}_{4}$ solutions at an average density of $300 \mathrm{~kg} \mathrm{~m}^{-3}$

\begin{tabular}{|c|c|c|c|c|}
\hline \multirow{2}{*}{$\begin{array}{l}\text { Initial } \\
\text { concentration/ } \\
\text { mass } \%\end{array}$} & \multirow{2}{*}{$\begin{array}{l}T /{ }^{\circ} \mathrm{C} \\
(\mathrm{G}-\mathrm{L}-\mathrm{S})\end{array}$} & \multicolumn{2}{|l|}{$\begin{array}{l}\text { Liquid } \\
\text { solution }\end{array}$} & \multirow{2}{*}{$\begin{array}{l}\begin{array}{l}\text { Vapor } \\
\text { solution }\end{array} \\
\rho / \mathrm{kg} \mathrm{m}^{-3}\end{array}$} \\
\hline & & $x /$ mass $\%$ & $\rho / \mathrm{kg} \mathrm{m}^{-3}$ & \\
\hline 0.140 & $372.4 \pm 0.1$ & $0.260 \pm 0.005$ & $435 \pm 2^{a}$ & $214 \pm 2^{a}$ \\
\hline 0.696 & $360.7 \pm 0.2$ & $1.02 \pm 0.01$ & $540 \pm 2^{a}$ & $148 \pm 2^{a}$ \\
\hline 1.39 & $352.5 \pm 0.2$ & $1.86 \pm 0.02$ & $594 \pm 2^{a}$ & $120 \pm 2^{a}$ \\
\hline 2.75 & $342.2 \pm 0.1$ & $3.47 \pm 0.02$ & $652 \pm 2^{a}$ & $95.7 \pm 2^{a}$ \\
\hline 6.69 & $326.6 \pm 0.3$ & $7.96 \pm 0.05$ & $755 \pm 2^{a}$ & $70.6 \pm 2^{a}$ \\
\hline 15.0 & $305.7 \pm 0.1$ & $17.1 \pm 0.1$ & $884 \pm 2^{a}$ & $50.5 \pm 2^{a}$ \\
\hline
\end{tabular}

${ }^{a}$ Obtained from interpolation of data from Khaibullin and Novikov. ${ }^{29}$

obtained from the DSC measurements is in excellent accordance with the literature data. The metastable liquid-liquid immiscibility has not been observed. This is in accordance with Valyashko et $a l .{ }^{35}$ suggesting the immiscibility to be suppressed by the appearance of the solid phase.

\section{$\mathrm{K}_{2} \mathrm{SO}_{4}-\mathrm{H}_{2} \mathrm{O}$}

$\mathrm{K}_{2} \mathrm{SO}_{4}$ is a type $2 \mathrm{~d}^{\prime}$ salt like $\mathrm{Na}_{2} \mathrm{SO}_{4}$ and therefore the DSC experiments showed quite similar results. Interestingly the transition temperatures for the appearance of the solid phase are much higher compared to the sodium salt. The liquid concentration was corrected with the method mentioned before. Liquid density data was extrapolated from the data of Puchkov et al. ${ }^{36}$ Because of the lack of data for the vapor density, we extrapolated the vapor pressures for the saturated solutions from the data of Ravich et $a l^{37}$ and used the corresponding vapor densities for pure steam obtained from the NIST database. ${ }^{38}$ The extrapolation of the liquid densities and the vapor pressures is subject to some uncertainty which we assume to be of the same magnitude as the uncertainty for the density measurements for the $\mathrm{Na}_{2} \mathrm{SO}_{4}$ system. Therefore we assumed an uncertainty for the densities of $\pm 2 \mathrm{~kg} \mathrm{~m}^{-3}$. The uncertainty in the liquid concentration was estimated as mentioned before. The measured and calculated values are shown in Table 2.

Our results are in good accordance with the few data sets available in the literature (Fig. 4), especially with the data of Ravich and Borovaya. ${ }^{39}$ Further measurements of densities are required to improve the correction of the measured DSC data. The DSC measurements also showed substantial superheating in this system, therefore all data was measured in the cooling mode.

\section{$\mathrm{K}_{2} \mathrm{HPO}_{4}$}

In the heating mode the heat flow curves showed an endothermic step-like transition with a positive $\Delta c_{\mathrm{V}}$ value followed by a second exothermic step with a negative $\Delta c_{\mathrm{V}}$ value (Fig. 6). The first transition is assigned to the appearance of a second liquid phase, leading to a liquid 1 - liquid 2 - gas equilibrium. The second transition is assigned to the critical endpoint $\mathrm{R}$, where the dilute liquid phase and the gas phase become equal. Supersaturation was also observed for the first transition, but to a much lower extent compared to the type 2 salts. For a solution 


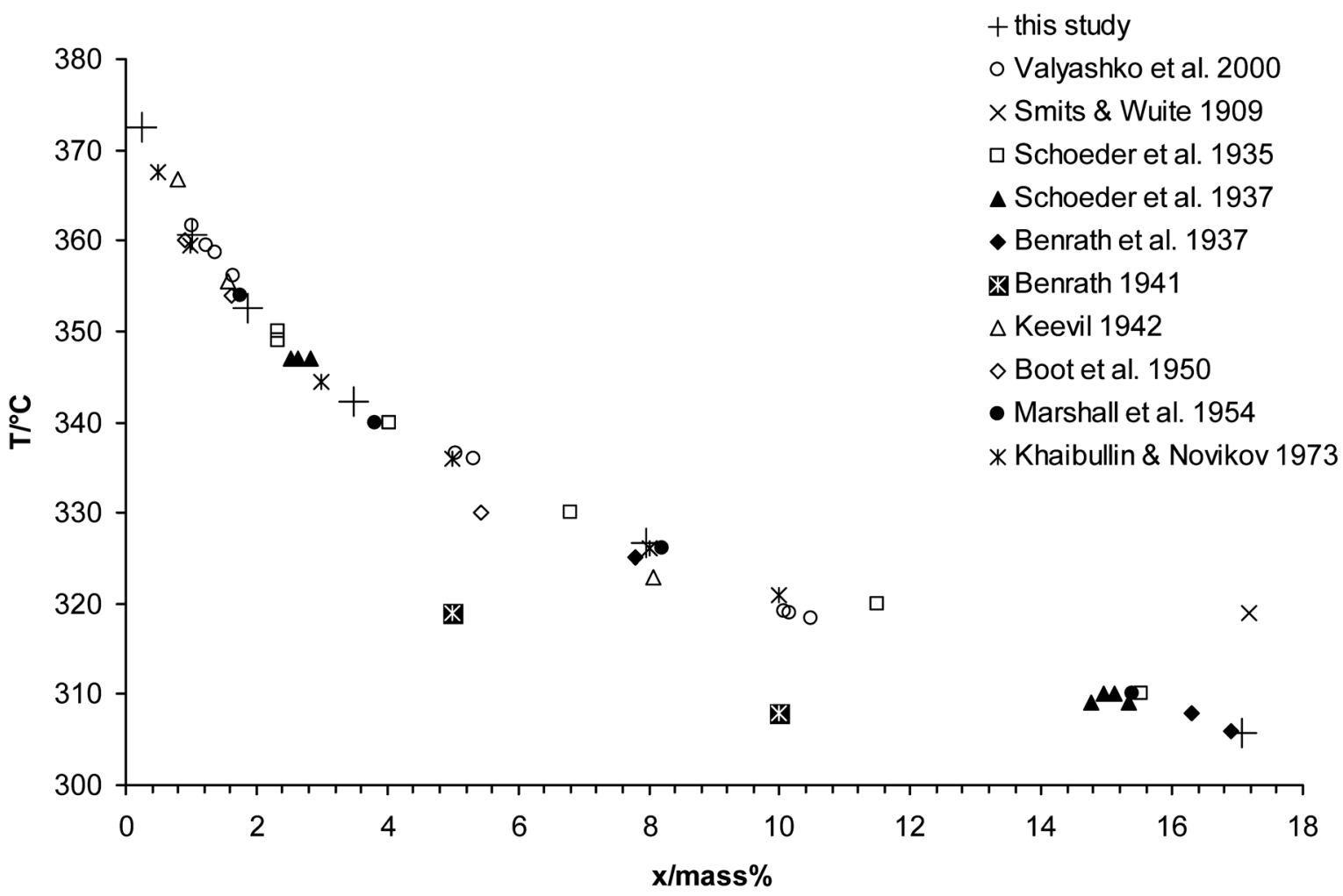

Fig. 3 Temperature-composition plot for the liquid at the three-phase equilibrium (G-L-S) of the system $\mathrm{Na}_{2} \mathrm{SO}_{4}+\mathrm{H}_{2} \mathrm{O}$.

Table 2 Results for $\mathrm{K}_{2} \mathrm{SO}_{4}$ solutions at an average density of $300 \mathrm{~kg} \mathrm{~m}^{-3}$

\begin{tabular}{|c|c|c|c|c|}
\hline \multirow{2}{*}{$\begin{array}{l}\text { Initial } \\
\text { concentration/ } \\
\text { mass } \%\end{array}$} & \multirow[b]{2}{*}{$T /{ }^{\circ} \mathrm{C}(\mathrm{G}-\mathrm{L}-\mathrm{S})$} & \multicolumn{2}{|l|}{$\begin{array}{l}\text { Liquid } \\
\text { solution }\end{array}$} & \multirow{2}{*}{$\begin{array}{l}\begin{array}{l}\text { Vapor } \\
\text { solution }\end{array} \\
\rho / \mathrm{kg} \mathrm{m}^{-3}\end{array}$} \\
\hline & & $x /$ mass $\%$ & $\rho / \mathrm{kg} \mathrm{m}^{-3}$ & \\
\hline 0.864 & $371.7 \pm 0.2$ & $1.69 \pm 0.03$ & $565 \pm 2^{a}$ & $196 \pm 2^{b}$ \\
\hline 1.72 & $367.7 \pm 0.1$ & $2.90 \pm 0.04$ & $586 \pm 2^{a}$ & $173 \pm 2^{b}$ \\
\hline 3.40 & $362.3 \pm 0.6$ & $5.19 \pm 0.05$ & $615 \pm 2^{a}$ & $148 \pm 2^{b}$ \\
\hline 5.04 & $358.9 \pm 0.1$ & $7.34 \pm 0.07$ & $639 \pm 2^{a}$ & $137 \pm 2^{b}$ \\
\hline 8.19 & $353.5 \pm 0.1$ & $11.4 \pm 0.1$ & $691 \pm 2^{a}$ & $121 \pm 2^{b}$ \\
\hline
\end{tabular}

${ }^{a}$ Obtained from extrapolation of data from Puchkov et $a l .{ }^{36}{ }^{b}$ Obtained from extrapolation of the vapor pressures from Ravich et $a .^{37}$ and calculation by the NIST Chemistry Webbook. ${ }^{38}$

with the concentration of 1.72 mass \% the signal appeared at $372.3 \pm 0.9{ }^{\circ} \mathrm{C}$ in the heating mode and at $371.4 \pm 0.1{ }^{\circ} \mathrm{C}$ in the cooling mode. Hence, all the temperatures given in Table 3 were measured in the cooling mode.

As in the measurements with the sulfate solutions the $\lambda$-shape of the second transition was less distinct in the heating mode compared to the cooling mode.

No phase density data is available in the literature for this system and therefore the correction for the liquid phase concentration could not be applied. Comparing our measurements to those of Marshall et al. ${ }^{\mathbf{4 0 , 4 1}}$ which were also taken at isochoric conditions, but probably at higher densities, we see a consistent trend of the data points (Fig. 5). This is especially the case if we assume that all data points in this study have to be corrected to higher concentrations.

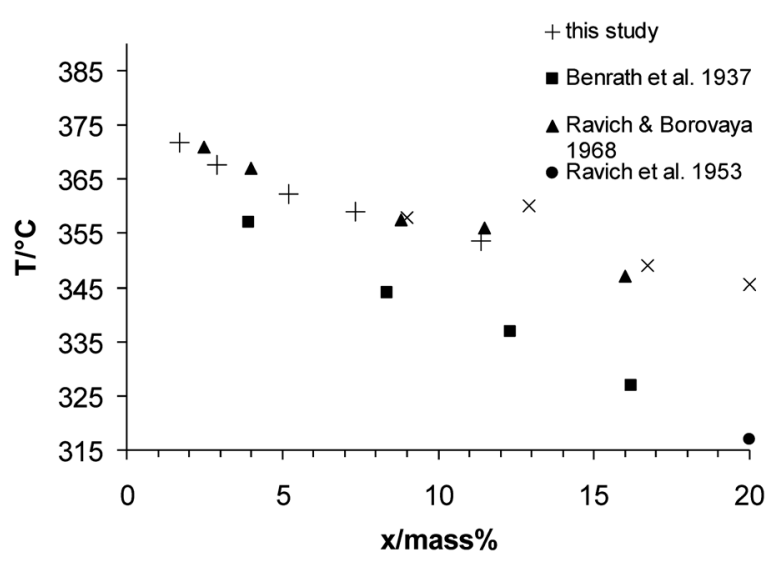

Fig. 4 Temperature-composition plot for the liquid at the three-phase equilibrium (G-L-S) of the system $\mathrm{K}_{2} \mathrm{SO}_{4}+\mathrm{H}_{2} \mathrm{O}$.

$\mathrm{K}_{2} \mathrm{SO}_{4}-\mathrm{Na}_{2} \mathrm{SO}_{4}-\mathrm{H}_{2} \mathrm{O}$

Interestingly, in our investigations of the ternary system $\mathrm{K}_{2} \mathrm{SO}_{4}-$ $\mathrm{Na}_{2} \mathrm{SO}_{4}-\mathrm{H}_{2} \mathrm{O}$ we found heat flow curves resembling those of the

Table 3 Results for $\mathrm{K}_{2} \mathrm{HPO}_{4}$ solutions at an average density of $300 \mathrm{~kg} \mathrm{~m}^{-3}$

Initial

concentration $/$ mass $\%$

$T /{ }^{\circ} \mathrm{C}(\mathrm{G}-\mathrm{L} 1-\mathrm{L} 2)$

0.434

$376.7 \pm 0.1$

0.865

$374.8 \pm 0.1$

1.72

$371.4 \pm 0.1$

3.96

$366.6 \pm 0.1$

6.46 


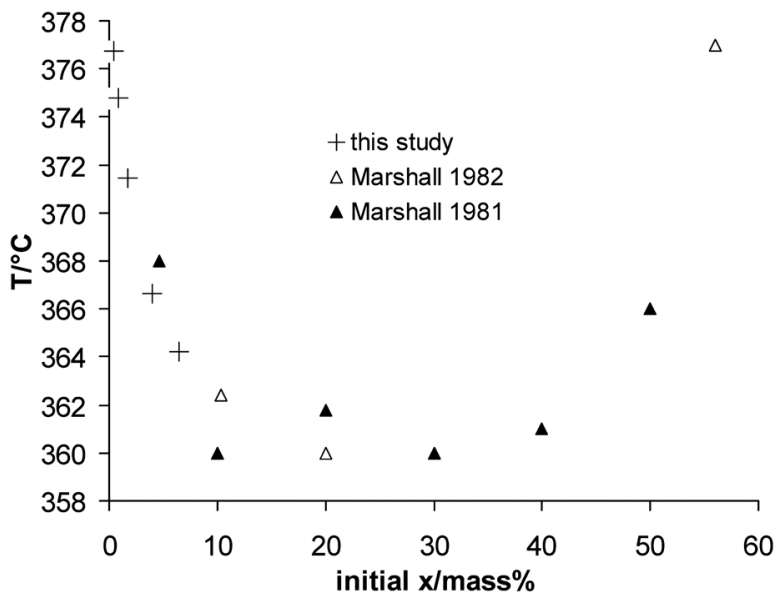

Fig. 5 Temperature-initial composition plot for the liquid at the three-phase equilibrium (G-L1-L2) of the system $\mathrm{K}_{2} \mathrm{HPO}_{4}+\mathrm{H}_{2} \mathrm{O}$.

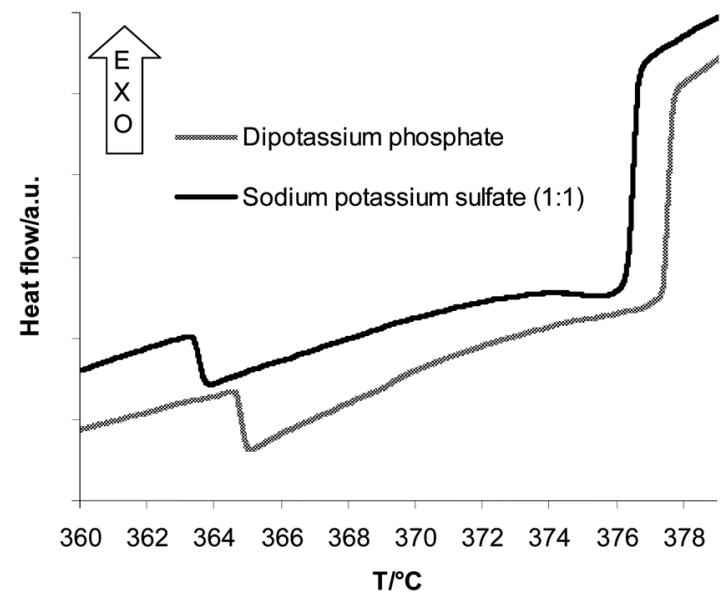

Fig. 6 Comparison of the heat flow curves of a $\mathrm{K}_{2} \mathrm{HPO}_{4}(6.46$ mass\%) solution and a $\mathrm{Na}-\mathrm{K} \mathrm{SO}_{4}(1: 1)$ solution.

measurements with the $\mathrm{K}_{2} \mathrm{HPO}_{4}-\mathrm{H}_{2} \mathrm{O}$ system. The first signal upon heating is an endothermic step with positive $\Delta c_{\mathrm{V}}$ value and the second signal is an exothermic step with negative $\Delta c_{\mathrm{V}}$ (Fig. 6). Therefore we assume that in mixed solutions of $\mathrm{K}_{2} \mathrm{SO}_{4}$ and $\mathrm{Na}_{2} \mathrm{SO}_{4}$ a liquid-liquid immiscibility occurs. The $\lambda$-shape of the second transitions was not clearly visible in the heating mode. As in the whole concentration range of our investigations (Table 4) we did not see any precipitation of a solid phase but

Table 4 Results for $\mathrm{K}_{2} \mathrm{SO}_{4}-\mathrm{Na}_{2} \mathrm{SO}_{4}-\mathrm{H}_{2} \mathrm{O}$ at an average density of $300 \mathrm{~kg} \mathrm{~m}^{-3}$, measured in the heating mode

\begin{tabular}{|c|c|c|c|c|}
\hline $\begin{array}{l}\text { Initial } \\
\text { concentration } \\
\left(\mathrm{Na}_{2} \mathrm{SO}_{4}\right) / \\
\text { mass } \%\end{array}$ & $\begin{array}{l}\text { Initial } \\
\text { concentration } \\
\left(\mathrm{K}_{2} \mathrm{SO}_{4}\right) / \\
\text { mass\% }\end{array}$ & $\begin{array}{l}\text { Molar } \\
\text { ratio } \\
\mathrm{K}: \mathrm{Na}\end{array}$ & $T /{ }^{\circ} \mathrm{C}(\mathrm{G}-\mathrm{L} 1-\mathrm{L} 2)$ & $T /{ }^{\circ} \mathrm{C}(\mathrm{G}-\mathrm{L})$ \\
\hline 0.699 & 1.71 & $2: 1$ & $367.79 \pm 0.07$ & $376.93 \pm 0.03$ \\
\hline 1.40 & 0.857 & $1: 2$ & $363.20 \pm 0.06$ & $376.25 \pm 0.01$ \\
\hline 1.39 & 1.70 & $1: 1$ & $363.54 \pm 0.07$ & $376.52 \pm 0.02$ \\
\hline 0.688 & 3.38 & $4: 1$ & $367.09 \pm 0.01$ & $376.99 \pm 0.01$ \\
\hline
\end{tabular}

only the liquid-liquid immiscibility, we conclude that the ternary solutions of potassium and sodium sulfate behave like a binary type $1 \mathrm{~d}$ solution.

The immiscibility may arise through the metastable states which are reported for the binary solutions of sodium and potassium sulfate. A similar effect has been reported for the system $\mathrm{K}_{2} \mathrm{SO}_{4}-\mathrm{Li}_{2} \mathrm{SO}_{4}-\mathrm{H}_{2} \mathrm{O} .{ }^{42-44}$ This liquid-liquid immiscibility was observed at all molar ratios $\mathrm{K}: \mathrm{Na}$ from $1: 2$ to $4: 1$.

\section{Conclusions}

Isochoric high pressure differential scanning calorimetry proved to be a relatively simple and fast method to investigate the phase behavior of aqueous salt solutions. It has the drawback that liquid and vapor densities have to be known to correct the data for the liquid concentration. Different phase transitions, such as the precipitation of a solid salt or the appearance of a second liquid phase, can easily be distinguished in the heating mode. We acquired new data in the low concentration range and reported the first calorimetric measurements on liquid-liquid immiscibilities in hydrothermal salt solutions. Furthermore we were able to find such phenomena also in the ternary $\mathrm{K}_{2} \mathrm{SO}_{4}-\mathrm{Na}_{2} \mathrm{SO}_{4}-\mathrm{H}_{2} \mathrm{O}$ system, which exhibits a pseudo type $1 \mathrm{~d}$ behavior, even though it consists of two type 2 salts. Such changes in the phase behavior of mixed salt solutions offer an opportunity for optimizing the salt separation process for SCWO and SCWG applications, as type 1 salt solutions can be separated and recovered efficiently. Hence, the addition of additional salts to a feed solution might change the phase behavior e.g. of a type 2 solution in such a way that no solid salts precipitate and that the separation can be conducted successfully. Nevertheless more studies on higher order mixtures are necessary to explore the possibilities and limits of this proposed technique of enhancing salt separation in SCW processes. The lack of density data for gas and liquid phases at hydrothermal conditions is currently a limitation, as this data is needed to fully interpret the isochoric DSC measurements.

\section{Abbreviations}

$\begin{array}{ll}\mathrm{G} & \text { Gas/vapor phase } \\ \mathrm{L} & \text { Liquid phase } \\ \mathrm{S} & \text { Solid phase } \\ \mathrm{F} & \text { Supercritical fluid } \\ c_{\mathrm{V}} & \text { Isochoric specific heat capacity } \\ \Phi & \text { Heat flow } \\ \beta & \text { Heating rate } \\ m & \text { Sample mass. }\end{array}$

\section{Acknowledgements}

The authors are very grateful to S. Pin, T. Huthwelker, T. Driesner (ETH Zurich) and A. Wokaun for fruitful discussions. This work was financially supported by the Swiss National Science Foundation (SNF) under SNF grant \#200021_132320. 


\section{Notes and references}

1 D. Coumou, T. Driesner and C. A. Heinrich, Science, 2008, 321(5897), 1825-1828.

2 P. A. Marrone, M. Hodes, K. A. Smith and J. W. Tester, J. Supercrit. Fluids, 2004, 29(3), 289-312.

3 M. Hodes, P. A. Marrone, G. T. Hong, K. A. Smith and J. W. Tester, J. Supercrit. Fluids, 2004, 29(3), 265-288.

4 A. A. Peterson, F. Vogel, R. P. Lachance, M. Froling, M. J. Antal, Jr and J. W. Tester, Energy Environ. Sci., 2008, 1(1), 32-65.

5 F. Vogel, in Handbook of Green Chemistry Volume 2 Heterogeneous Catalysis, ed. P. Anastas and R. Crabtree, Wiley-VCH, Weinheim, 2009, vol. 2, ch. 12, pp. 281-324.

6 V. M. Valyashko, in Hydrothermal Experimental Data, John Wiley \& Sons, Ltd, 2008, pp. 1-133.

7 V. Valyashko, in Aqueous Systems at Elevated Temperatures and Pressures, ed. D. Palmer, R. Fernández-Prini and A. H. Harvey, Academic Press, London, 2004, pp. 597-641.

8 D. Freyer and W. Voigt, Geochim. Cosmochim. Acta, 2004, 68(2), 307-318.

9 M. Schubert, J. Aubert, J. B. Müller and F. Vogel, J. Supercrit. Fluids, 2012, 61, 44-54.

10 M. Schubert, J. W. Regler and F. Vogel, J. Supercrit. Fluids, 2010, 52(1), 99-112.

11 M. Schubert, J. W. Regler and F. Vogel, J. Supercrit. Fluids, 2010, 52(1), 113-124.

12 A. A. Peterson, P. Vontobel, F. Vogel and J. W. Tester, J. Supercrit. Fluids, 2008, 43(3), 490-499.

13 A. A. Peterson, P. Vontobel, F. Vogel and J. W. Tester, J. Supercrit. Fluids, 2009, 49(1), 71-78.

14 A. A. Peterson, J. W. Tester and F. Vogel, J. Supercrit. Fluids, 2010, 54(2), 250-257.

15 I. Leusbrock, S. J. Metz, G. Rexwinkel and G. F. Versteeg, J. Supercrit. Fluids, 2010, 53(1-3), 17-24.

16 I. Leusbrock, S. J. Metz, G. Rexwinkel and G. F. Versteeg, J. Supercrit. Fluids, 2010, 54(1), 1-8.

17 G. Akgul and A. Kruse, J. Supercrit. Fluids, 2012, 66, 207-214.

18 A. Kruse, D. Forchheim, M. Gloede, F. Ottinger and J. Zimmermann, J. Supercrit. Fluids, 2010, 53(1-3), 64-71.

19 F. J. Armellini and J. W. Tester, Fluid Phase Equilib., 1993, 84, 123-142.

20 F. J. Armellini, J. W. Tester and G. T. Hong, J. Supercrit. Fluids, 1994, 7(3), 147-158.

21 P. Whiting, U.S. Pat., 5667698 A, 1997.
22 I. Abdulagatov, V. Dvoryanchikov, B. Mursalov and A. Kamalov, Fluid Phase Equilib., 1998, 143, 525-535.

23 K. G. Kravchuk and K. Todheide, Z. Phys. Chem., 1996, 193, 139-150.

24 A. A. Rouff, S. Rabe and F. Vogel, J. Supercrit. Fluids, 2011, 57(3), 207-212.

25 A. Benrath, Z. Anorg. Allg. Chem., 1941, 247, 147-160.

26 A. Benrath, F. Gjedebo, B. Schiffers and H. Wunderlich, Z. Anorg. Allg. Chem., 1937, 231, 285-297.

27 H. Booth and R. Bidwell, J. Am. Chem. Soc., 1950, 72, 25672575.

28 N. Keevil, J. Am. Chem. Soc., 1942, 64, 841-850.

29 I. K. Khaibullin and B. Novikov, High Temp., 1973, 11, 276-282.

30 W. L. Marshall, H. Wright and C. Secoy, J. Chem. Educ., 1954, 31, 34-36.

31 W. Schroeder, A. Berk and E. Partridge, J. Am. Chem. Soc., 1935, 57, 1783-1790.

32 W. Schroeder, A. Berk and E. Partridge, J. Am. Chem. Soc., 1937, 59, 1790-1795.

33 A. Smits and J. Wuite, Proc. R. Soc. Amsterdam, 1909, 12, 244257.

34 W. Tilden and W. Shenstone, Proc. R. Soc. London, Ser. A, 1883, 35, 345-346.

35 V. M. Valyashko, I. M. Abdulagatov and J. M. H. Levelt Sengers, J. Chem. Eng. Data, 2000, 45(6), 1139-1149.

36 L. V. Puchkov, V. V. Kurochkina, and R. P. Matveeva, Deposit. VINITI USSR, 1976, n.3474-76 Dep., p. 20.

37 M. I. Ravich, F. Borovaya and V. Y. Ketkovich, Izv. Sekt. Fiz.Khim. Anal., Inst. Obshch. Neorg. Khim., Akad. Nauk SSSR, 1953, 20, 225-239.

38 NIST Chemistry WebBook, NIST Standard Reference Database Number 69, ed. P. J. Linstrom and W. Mallard, National Institute of Standards and Technology, retrieved February 13, 2013.

39 M. I. Ravich and F. E. Borovaya, Zh. Neorg. Khim., 1968, 13, 1418-1425.

40 W. L. Marshall, C. Hall and R. E. Mesmer, J. Inorg. Nucl. Chem., 1981, 43, 722-728.

41 W. L. Marshall, J. Chem. Eng. Data, 1982, 27(2), 175-180.

42 M. Ravich and V. Valyashko, Zh. Neorg. Khim., 1969, 14, 1650-1654.

43 M. Urusova and V. Valyashko, Russ. J. Phys. Chem., 2012, 57(4), 579-591.

44 V. M. Valyashko, Zh. Neorg. Khim., 1975, 20(4), 11291131. 